\title{
CONGENER-SPECIFIC BIOACCUMULATION OF PCBs IN DIFFERENT WATER BIRD SPECIES
}

\author{
Gaby Zimmermann*, Daniel R. Dietrich, Peter Schmid and Christian Schlatter \\ Institute of Toxicology, Swiss Federal Institute of Technology and University of Zürich, \\ Schorenstr. 16, CH-8603 Schwerzenbach, Zürich, Switzerland
}

\begin{abstract}
The bioaccumulation behaviour of single PCB congeners in three trophic levels of a food chain in an aquatic ecosystem was studied. Congener-specific biotransfer factors were calculated comparing PCB concentrations in tissues of 4 water bird species with the contents measured in their food source. The coplanar PCBs were of particular interest.

The maximum concentrations of individual PCB congeners detected in mussels, fish and birds were $0.5,4$, and $26 \mu \mathrm{g} / \mathrm{g}$ extractable lipids, respectively. In general, the mussel-feeding tufted ducks showed lower PCB levels than the fish-feeding bird species. The biotransfer factors were highest for the non-ortho chlorosubstituted coplanar PCB congeners from lake trout to grey herons ( 3 to 15 , depending on the congener).

If the TCDD toxic equivalency (TEq) concept based on mammalian toxicity data is used for the toxicological assessment the detected PCB levels are in the range where effects on the reproductive impairment of theses bird species could result. However, no indication for such effects could be observed. This suggests that species-specific TEF values are required.
\end{abstract}

\section{KEYWORDS}

Polychlorinated biphenyls, coplanar congeners, zebra mussels, fish, water birds, bioaccumulation, risk assessment, reproductive impairment

* to whom correspondence should be addressed 


\section{INTRODUCTION}

Water birds are exposed to various halogenated compounds such as DDT and PCBs. The high levels especially of the PCBs have occasionally resulted in a number of adverse effects on the reproductive potential of adults as well as developmental and toxic effects such as malformations and lethality to embryos [1-3] possibly leading to population declines $[4,5]$.

However, most investigations so far have been limited to the top predator species. The situation at the preceding trophic levels remains unknown in most cases. Because of their biochemical activity similar to the highly toxic 2,3,7,8-TCDD, the non-ortho chloro-substituted coplanar PCB congeners are of particular interest. This activity seems to be mediated by interaction with the Ah-receptor. Based on the similarities, the concept of toxic equivalency factors (TEFs) and resulting TCDD toxic equivalents (TEqs) [6] should be applicable also for the toxicological assessment of the observed PCB levels.

The bioaccumulation behaviour of PCBs through the food chain and the transfer of PCB congeners from one trophic level to the next higher was investigated. Species-specific PCB patterns including the mono- and non-ortho substituted congeners and organ-specific differences in content and/or congener patterns between liver and muscle tissue gave a basis for the assessment of the potential health hazards for different trophic levels.

\section{MATERIALS AND METHODS}

\section{Sample collection}

All samples were collected in 1993 in the Linth channel region in Switzerland. The Linth channel is the fast flowing drain of the relatively clean and oligotrophic I,ake Walen. This mainly agricultural area is virtually free of industrialisation.

Species of interest were zebra mussel (Dreissena polymorpha), brown trout (Salmo trutta fario), tufted duck (Aythya fuligula), great crested grebe (Podiceps cristatus), grey heron (Ardea cinerea) and cormorant (Phalacrocorax carbo sinensis). Individuals of all the investigated species were collected at the same time in spring, autumn and winter, respectively.

\section{Materials}

Anhydrous sodium sulphate (puriss. p.a.), potassium hydroxide, ethanol, silica gel 60, sulphuric acid (puriss. p.a.), and cesium hydroxide (pract. $95 \%$ ) were from Fluka AG, CH-9470 Buchs. Activated carbon Super A AX-21 was obtained from Anderson (Adrian, MI 49221-3499, USA). All solvents used (dichloromethane, $\mathrm{n}$-hexane, toluene, isooctane) were of trace residue analytical grade (Burdick \& Jackson, destilled in glass, Fluka AG). The reference PCB congeners were obtained from Amchro Restek Europa GmbH (D-65837 Sulzbach). The ${ }^{13} \mathrm{C}$-labelled PCB congeners nos. 77, 118, 126, and 169 were obtained from Cambridge Isotope Laboratories (Woburn, MA 01801 USA). 


\section{Sample preparation}

Extended versions of the analytical procedure will be described and discussed elsewhere [7, 8]. A sample aliquot (1 gram) was spiked with the ${ }^{13} \mathrm{C}$-labelled PCBs (internal standard) and ground to powder in a mortar together with the five-fold amount of anhydrous sodium sulphate. The sample was then packed into a glass column $(0.8 \mathrm{~cm}$ - inner diameter) and eluted with dichloromethane. The volume of the extract was reduced to approx. $1 \mathrm{ml}$ in a rotary evaporator (bath temperature $40^{\circ} \mathrm{C}, 6.5 \mathrm{~Pa}$ ). Final evaporation of the solvent was attained by careful application of a stream of purified nitrogen. The lipid content of the sample was determined gravimetrically. The fat extracts were saponified with $1 \%(w / v)$ potassium hydroxide in ethanol $\left(100^{\circ} \mathrm{C}, 30\right.$ minutes) and then extracted with n-hexane. After purification by passing through silica gel impregnated with sulphuric acid, the sample was fractionated on activated carbon into three fractions containing the di- to tetra-, mono-, and non-ortho PCB congeners, respectively.

\section{Instrumental analysis, identification and quantification}

The di- to tetra-ortho fractions were analysed using gas chromatography/electron capture detection (GCECD), whereas the mono- and non-ortho fractions were analysed with gas chromatography/high resolution mass spectrometry (GC-HRMS). Congeners were identified by co-chromatography with reference PCB congeners. The quantification was carried out by comparison of the peak areas with those of external (GCECD) or ${ }^{13} \mathrm{C}$-labelled internal (GC-HRMS) standards. The PCB congeners determined were IUPAC no. 28 (2,4,4'-trichlorobiphenyl), 37 (3,4,4'-trichlorobiphenyl), 52 (2,2',5,5'-tetrachlorobiphenyl), 70 (2,3',4',5tetrachlorobiphenyl), 77 (3,3',4,4'-tetrachlorobiphenyl), 81 (3,4,4',5-tetrachlorobiphenyl), 101 (2,2',4,5,5'pentachlorobiphenyl), 105 (2,3,3',4,4'-pentachlorobiphenyl), 114 (2,3,4,4',5-pentachlorobiphenyl), 118 $\left(2,3^{\prime}, 4,4^{\prime}, 5\right.$-pentachlorobiphenyl), 126 (3,3',4,4',5-pentachlorobiphenyl), 138 (2,2',3,4,4',5'-hexachlorobi-

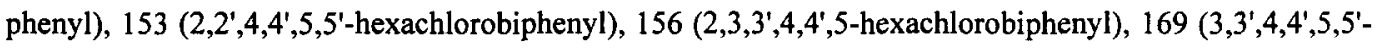
hexachlorobiphenyl), and $180\left(2,2^{\prime}, 3,4,4^{\prime}, 5,5^{\prime}\right.$-heptachlorobiphenyl).

\section{The TEF concept used for risk assessment}

The individual TEq (TCDD toxic equivalency) values were calculated by multiplication of the concentrations by the corresponding TEF (toxic equivalence factor) based on mammalian toxicity data [9]. A total TCDD-TEq value was calculated as the sum of the individual TEq values of 12 PCB congeners quantified in the biological samples.

Depending on the TEF concept used the contribution of the individual PCB congeners and consequently the total TEq can vary greatly. Using for example the WHO TEFs [10], the total TEq determined in this study would be approximately fifty percent lower (Table 1). Multiplication with the actual TEFs by Safe [11] will lead to another most important mono-ortho congener, namely the PCB no. 105 which seem to contribute more to the toxicity than congener no. 118. In this study we decided to calculate the TEq values by multiplication with the mammalian TEFs by Safe [9] to get a useful basis for a better comparability with literature. 


\section{RESULTS AND DISCUSSION}

Table 1 shows the levels of PCB congeners in the muscle tissue of the 4 different bird species investigated. The data presented demonstrate the large variability of $\mathrm{PCB}$ levels found within a single species. The results are in the range of wildlife levels reported in the literature $[12,13]$. Besides individual differences in the feeding habits this variability can be due to the age of the individuals and to a seasonal variation of the food composition (the birds were shot in spring, autumn, and winter). After these birds were shot in wild life and their age is not known; an age dependence cannot be verified. A seasonal influence was not generally visible: only the grey herons show slightly higher PCB levels in spring than in summer and winter (single values not shown).

\section{Species differences}

Great crested grebes, grey herons, and cormorants are fish eating birds, whereas the tufted ducks feed on zebra mussels exclusively. Table 1 shows that the fish eating bird species show higher PCB levels than the mussel feeding ducks.

This can be explained by the fact that fish belong to a higher trophic level than mussels. Herons and cormorants exhibit higher PCB body burdens than grebes. Herons and cormorants feed on bigger i.e. older fish which contain higher PCB levels than young fish which are preferred by the grebes.

The levels of the cormorant given in Table 1 are relatively low as compared to literature data for European cormorants which are in the range of $24-301 \mu \mathrm{g} / \mathrm{g}$ lipid weight [14]. As the cormorant is a bird species migrating to breeding colonies in Denmark during the summer months the residence time of 4 to 6 months in the comparatively lower contaminated Swiss aquatic ecosystem may be sufficient to decrease a body burden built up in a higher contaminated area.

\section{Organ differences}

The concentrations of single PCB congeners measured in muscle tissues of the different bird species are shown in Table 1. The results of earlier measurements of the liver tissue PCB content (based on lipid weight) in the same birds (data not published) were similar to the levels in muscle tissue.

Apparently there is no significant difference between the concentrations or the pattern of PCB congeners between these two selected organs. This suggests that PCB congeners are homogeneously distributed in the lipids of the body.

\section{$P C B$ patterns and bioaccumulation}

For reasons of comparison with literature data of the toxicity of PCB congeners the TEF concept of Safe [9] . derived from mammalian toxicity data was used.

In the investigated bird species the total TEq value is composed by 2 to $4 \%$ contribution by the di-ortho, 43 to $67 \%$ by the mono-ortho, and 32 to $55 \%$ by the non-ortho substituted congeners. The major contributor within the mono-ortho congeners is PCB no. 118. Besides, the PCB patterns found in this study were similar to those reported in the literature [12]. 


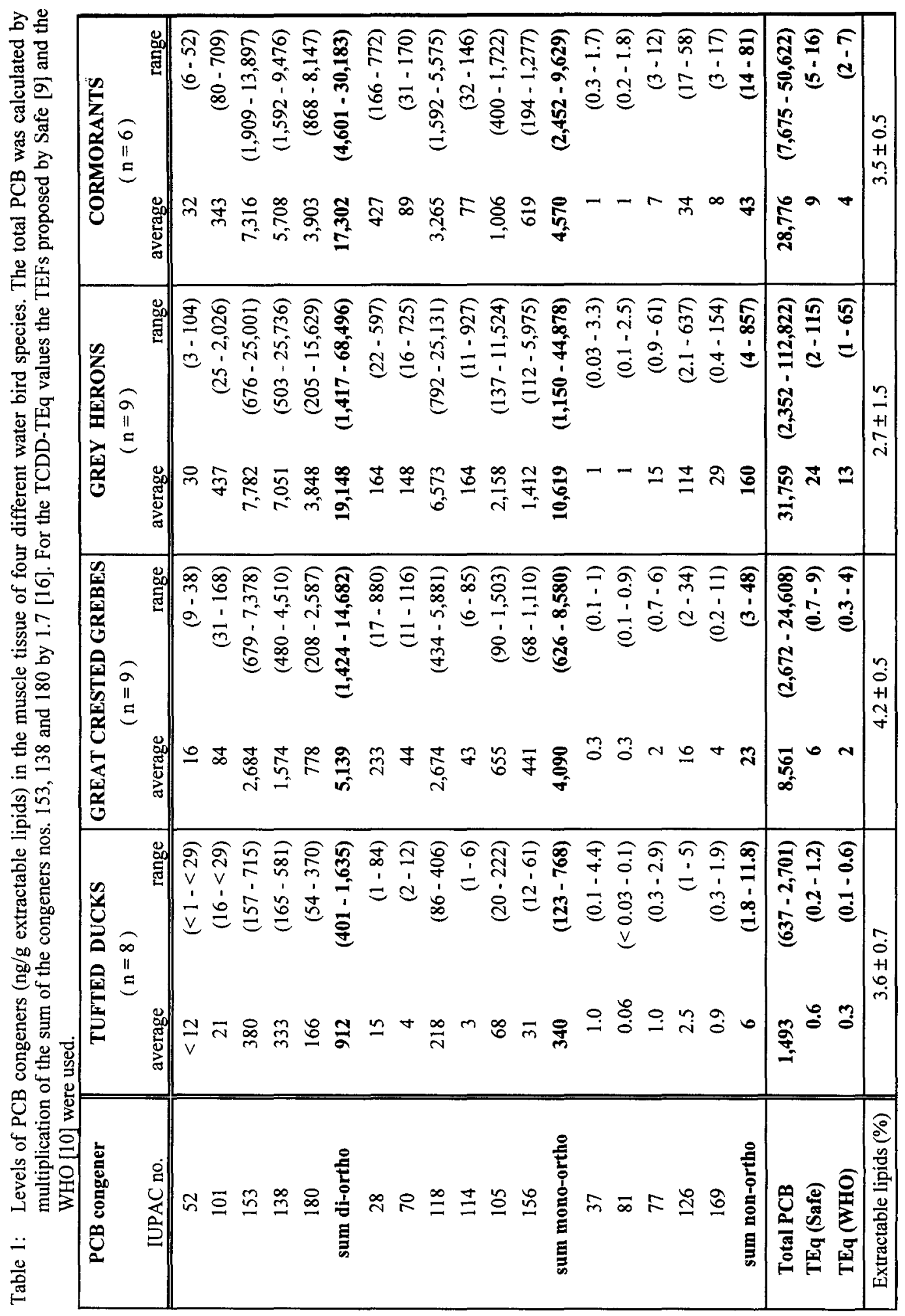


The bioaccumulation behaviour of the coplanar non-ortho substituted PCBs is of particular interest. The concentrations of these congeners relative to the total PCB content did not significantly increase with higher trophic levels. However, in herons the contribution of the coplanar congeners relative to the total PCB content was higher than in tufted ducks. This may indicate that while the pattern of the remaining congeners does not change, the coplanar PCBs may have a slightly higher tendency for bioaccumulation through the food chain.

The higher levels of PCB no. 77 in tufted ducks compared to the other coplanar PCBs could be due to lower metabolic capacity of some duck species for certain planar congeners [15]. On the other hand, the differences in PCB body burdens between bird species suggest that the PCB pattern is influenced by individual dietary factors rather than by species differences in the bioaccumulation.

Table 2 shows the concentrations of PCB congeners in the food sources of the bird species investigated. Comparison of these values of the total PCB content with the PCB levels detected in the birds allow a calculation of a mean biotransfer factor (BTF) of approximately 3 between zebra mussel and tufted ducks.

It was not possible to calculate a transfer factor for the great crested grebes from the fish data presented in Table 2. Great crested grebes feed on juvenile fish, whereas the values in Table 2 are those of adult fish. In comparison, the biotransfer factors from fish to grey herons ranged from 3 to 15 , depending on the individual congener. The biotransfer factors of the sum of the non-ortho substituted PCB congeners were higher $(\mathrm{BTF}=9)$ than of the mono-ortho congeners $(\mathrm{BTF}=6)$ and of the di-ortho congeners $(\mathrm{BTF}=4)$. Within the coplanar PCBs, congener no. 169 seems to have the highest biotransfering potency (BTFs for congeners nos. 77,126 and 169 from trout to heron were 3,11 and 15 , respectively).

The total PCB content observed in one single egg of a great crested grebe was $18 \pm 4 \mu \mathrm{g} / \mathrm{g}$ extractable lipids (number of analyses $=3$ ). The biotransfer factors of individual PCB congeners from the female grebe to the egg indicating the maternal transfer ranged between 1 and 4

\section{Toxicological evaluation and risk assessment with respect to reproductive effects}

In wildlife species the reproductive impairment is a relatively easily observable biological indicator for toxic effects of environmental xenobiotics; more subtle effects like organ toxicities require pathophysiological examination of individuals.

The total PCB contents of bird species can be compared to those of species which already show impairment of their reproduction (e.g. reducing pup number and size, hatchability, occurrence of deformities), and thus give an indication as to how close the bird species of interest is to become endangered by toxic effects of PCBs.

A first comparison of our data was performed to those of the mammalian species fish otter (Lutra lutra). This top predator and fish consumer is now extinct in Switzerland. PCB contamination in the food sources of the otter is currently assumed to be responsible for the impaired reproduction of these animals. In livers of fish otters in critical areas total PCB levels between 2 to $190 \mu \mathrm{g} / \mathrm{g}$ lipid were detected. PCB concentrations of $50 \mu \mathrm{g} / \mathrm{g}$ lipid seem to represent the critical level for impaired reproduction of these mammals [17]. 
Table 2: Levels of PCB congeners (ng/g extractable lipids) in extracts of whole zebra mussels (Dreissena polymorpha) and muscle tissues of trout (Salmo trutta fario) from the Linth channel during 1992 to 1994. The total PCB was calculated by multiplication of the sum of the congeners 153,138 and 180 by 1.7 [16]. For the TCDD-TEq values the TEFs proposed by Safe [9] and the WHO [10] were used.

\begin{tabular}{|c|c|c|c|c|}
\hline \multirow{2}{*}{$\begin{array}{l}\text { PCB congener } \\
\text { IUPAC no. }\end{array}$} & \multicolumn{2}{|c|}{$\begin{array}{c}\text { ZEBRA MUSSELS } \\
(n=12)\end{array}$} & \multicolumn{2}{|c|}{$\begin{array}{l}\text { BROWN TROUTS } \\
(\mathrm{n}=14)\end{array}$} \\
\hline & average & range & average & range \\
\hline 52 & $<16$ & $(<1-51)$ & 126 & $(16-352)$ \\
\hline 101 & 84 & $(13-251)$ & 795 & $(132-1,736)$ \\
\hline 153 & 124 & $(32-403)$ & 1,558 & $(211-3,142)$ \\
\hline 138 & 142 & $(39-489)$ & 1,538 & $(307-3,862)$ \\
\hline 180 & 46 & $(10-150)$ & 592 & $(59-1,338)$ \\
\hline sum di-ortho & 413 & $(102-1,314)$ & 4,609 & $(723-9,819)$ \\
\hline 28 & $<11$ & $(<3-31)$ & 30 & $(6-145)$ \\
\hline 70 & $<10$ & $(<1-<26)$ & 110 & $(18-264)$ \\
\hline 118 & 89 & $(39-253)$ & 1,208 & $(207-3,418)$ \\
\hline 114 & $<10$ & $(<1-<26)$ & 10 & $(2-29)$ \\
\hline 105 & 13 & $(5-37)$ & 218 & $(33-586)$ \\
\hline 156 & 12 & $(4-29)$ & 179 & $(20-381)$ \\
\hline sum mono-ortho & 144 & $(61-395)$ & 1,754 & $(279-4,699)$ \\
\hline 37 & $<1$ & $(<0.3-<3)$ & 1 & $(0.1-5)$ \\
\hline 81 & $<1$ & $(<0.2-<3)$ & 0.3 & $(0.01-1)$ \\
\hline 77 & $<1$ & $(<0.2-<3)$ & 5 & $(0.6-17)$ \\
\hline 126 & $<1$ & $(<0.2-<3)$ & 11 & $(1.2-24)$ \\
\hline 169 & $<1$ & $(<0.2-<3)$ & 2 & $(0.2-5)$ \\
\hline sum non-ortho & $<5$ & $(<1-<16)$ & 18 & $(1-36)$ \\
\hline TOTAL PCB & 532 & $(143-1,768)$ & 6,270 & $(981-13,412)$ \\
\hline TEq (Safe) & $<0.29$ & $(<0.1-0.8)$ & 2.9 & $(0.4-7)$ \\
\hline TEq (WHO) & $<0.13$ & $(0.04-0.35)$ & 1.3 & $(0.2-3)$ \\
\hline Extractable lipids (\%) & & .18 & & 0.6 \\
\hline
\end{tabular}


If birds were as sensitive to PCBs as mammals, the observed levels of 2 to $113 \mu \mathrm{g} / \mathrm{g}$ lipid in the bird species reported here, e.g. great crested grebes, grey herons and cormorants, are supposed to lead to reproductive impairment. Indeed, in livers of cormorants showing reproductive impairment, the total PCB content was around $100 \mu \mathrm{g} / \mathrm{g}$ lipids [14]. The total PCB concentrations in bird species determined in the present study (Table 1, concentrations in muscle tissue are in the same range as the PCB contents in liver which are not published here) were in the same range, especially these of the grey herons and cormorants. Surprisingly, the investigated bird populations appear to be growing and in relatively good health condition (personal communication from the Swiss Ornithological Institute in Sempach). Thus, the total PCB level seems not to be a good indicator for PCB toxicity in birds. This can be due to the fact that not all bird species are equally sensitive to the toxic effects of PCBs, as already suggested earlier by Tillitt and coworkers [18], or it could be due to a species-specific pattern of toxic and non-toxic congeners which is not reflected by use of total PCBs as toxicological parameters.

In order to evaluate the toxicity of a $\mathrm{PCB}$ burden in an organism the $\mathrm{IEF}$ concept can be used for accounting for the different contributions of the individual congeners. The TEF concept is based supposing similar mechanisms of action of the individual PCB congeners. So far, PCB TEFs have been developed from mammalian data [9]. If these TEFs are applied nevertheless to the data given in Table 1 the resulting total 'Eqs are in the same range as levels in mammals for which reproductive impairment has been observed (1 to $16 \mathrm{ng} / \mathrm{g}$ lipid [19-21]).

In birds most data were so far reported for eggs or chicks. In eggs of cormorants and terns TEq values up to $12 \mathrm{ng} / \mathrm{g}$ lipid were found [22-24]. However, in most of these breeding colonies the hatching success of the eggs, one of the sensitive parameters for reproductive impairment, was not significantly reduced [22]. The TEq value found in the single egg of a great crested grebe presented in this study was even higher $(17 \mathrm{ng} / \mathrm{g}$ extractable lipids), but, as mentioned above, there were no indications of any known toxic effects in these bird populations, neither. The calculated TEq values (Table 1) for muscle tissue of the four investigated water bird species were in the same range ( $1-24 \mathrm{ng} / \mathrm{g}$ lipid) as reported in eggs of other water birds [20, 23 25].

It can be concluded that neither the total PCB level nor the total TEq is an appropriate basis for the toxicological assessment of the present data. This asks for the development of specific TEFs for birds. We anticipate that these TEFs will differ considerably from the respective mammalian values.

\section{ACKNOWLEDGEMENTS}

We thank the Jagd- und Fischereiverwaltung des Kantons St.Gallen, the diver, all fishermen and the hunter for their essential and friendly co-operation. This work was supported by the Swiss National Foundation grant no. 31-36445.92. 


\section{REFERENCES}

[1] Gilbertson, M., Kubiak, T., Ludwig, J., Fox, G. (1991): Great Lakes embryo mortality, edema, and deformities syndrome (GLEMEDS) in colonial fish-eating birds: similarity to chick-edema disease. J. Toxicol. Environ. Health 33: 455-520

[2] Sanderson, J. T., Elliott, J. E., Norstrom, R. J., Whitehead, P. E., Hart, L. E., Cheng, K. M., Bellward, G. D. (1994): Monitoring biological effects of polychlorinated dibenzo-p-dioxins, dibenzofurans, and biphenyls in great blue heron chicks (Ardea herodias) in British Columbia. J. Toxicol. Environ. Health 41 : 435-450

[3] Sanderson, J. T., Norstrom, R. J., Elliott, J. E., Hart, L. E., Cheng, K. M., Bellward, G. D. (1994): Biological effects of polychlorinated dibenzo-p-dioxins, dibenzofurans, and biphenyls in doublecrested cormorant chicks (Phalacrocorax auritus). J. Toxicol. Environ. Health 41: 247-265

[4] Giesy, J. P., Verbrugge, D. A., Othout, R. A., Bowerman, W. W., Mora, M. A., Jones, P. D., Newsted, J. L., Vandervoort, C., Heaton, S. N., Aulerich, R. J., Bursian, S. J., Ludwig, J. P., Dawson, G. A., Kubiak, T. J., Best, D. A., lillitt, D. E. (1994): Contaminants in fishes from Great Lakesinfluenced sections and above dams of three Michigan rivers. II. Implications for health of mink. Arch. Environ. Contam. Toxicol. 27: 213-223

[5] Wren, C. D. (1991): Cause-effect linkages between chemicals and populations of mink (Mustela vison) and otter (Lutra canadensis) in the Great Lakes basin. J. Toxicol. Environ. Health 33 : 549-585

[6] NATO/CCMS (1988): North Atlantic Treaty Organization (NATO)/committee on the challenges of modern society (CCMS), Report Number 176

[7] Schmid, P., Zimmermann, G., Schlatter, C. (1996): The fractionation of PCBs according to orthosubstitution. (in preparation)

[8] Zimmermann, G., Dietrich, D. R., Schmid, P., Schlatter, C. (1996): Coplanar PCB congener levels in zebra mussels (Dreissena polymorpha) and tufted ducks (Aythya fuligula). (in preparation)

[9] Safe, S. (1990): Polychlorinated biphenyls (PCBs), dibenzo-p-dioxins (PCDDs), dibenzofurans (PCDFs), and related compounds: environmental and mechanistic considerations which support the development of toxic equivalency factors (TEFs). Crit. Rev. Toxicol. 21 (1): 51-88

[10] Ahlborg, U. G., Becking, G. C., Birnbaum, L. S., Brouwer, A., Derks, H. J. G. M., Feeley, M., Golor, G., Hanberg, A., Larsen, J. C., Liem, A. K. D., Safe, S. H., Schlatter, C., Waern, F., Younes, M., Yrjänheikki, E. (1994): Toxic equivalency factors for dioxin-like PCBs. Chemosphere 28 (6): 1049-1067

[11] Safe, S. H. (1994): Polychlorinated biphenyls (PCBs): environmental impact, biochemical and toxic responses, and implications for risk assessment. Crit. Rev. Toxicol. 24 (2): 87-149

[12] Boumphrey, R. S., Harrad, S. J., Jones, K. C., Osborn, D. (1993): Polychlorinated biphenyl congener patterns from tissues from a selection of British birds. Arch. Environ. Contam. Toxicol. 25: 346352

[13] Rattner, B. A., Hatfield, J. S., Melancon, M. J., Custer, T. W., Tillitt, D. E. (1994): Relation among cytochrome $\mathrm{P} 450$, Ah-active PCB congeners and dioxin equivalents in pipping black-crowned night-heron embryos. Environ. Toxicol. Chem. 13 (11): 1805-1812

[14] Scharenberg, W. (1991): Cormorants (Phalacrocorax carbo sinensis) as bioindicators for polychlorinated biphenyls. Arch. Environ. Contam. Toxicol. 21: 536-540 
[15] Brouwer, A. (1991): The role of enzymes in regulating the toxicity of xenobiotics. Biochem. Soc. Transact. 19: 731-736

[16] DFG (1988): Polychlorierte Biphenyle: Bestandesaufnahme über Analytik, Vorkommen, Kinetik und Toxikologie. Mitteilung der Senatskommission zur Prüfung von Rückständen in Lebensmitteln. 13. VCH Verlagsgesellschaft mbH, D-69451 Weinheim (FRG).

[17] Mason, C. F., Ratford, J. R. (1994): PCB congeners in tissues of European otter (Lutra lutra). Bull. Environ. Contam. Toxicol. 53: 548-554

[18] Tillitt, D. E., Kubiak, T. J., Ankley, G. T., Giesy, J. P. (1993): Dioxin-like toxic potency in Forster's tern eggs from Green Bay, Lake Michigan, North America. Chemosphere 26 (11): 2079-2084

[19] Falandysz, J., Yamashita, N., Tanabe, S., Tatsukawa, L., Rucinska, L., Skora, K. (1994): Congenerspecific data on polychlorinated biphenyls in tissues of common porpoise from Puck Bay, Baltic Sea. Arch. Environ. Contam. Toxicol. 26: 267-272

[20] Kuehl, D. W., Haebler, R., Potter, C. (1994): Coplanar PCB and metal residues in dolphins from the U.S. Atlantic coast including Atlantic bottlenose obtained during the 1987/88 mass mortality. Chemosphere 28 (6): 1254-1253

[21] Leonards, P. E. G., Van Hattum, B., Cofino, W. P., Brinkman, U. A. T. (1994): Occurrence of nonortho-, mono-ortho- and di-ortho-substituted PCB congeners in different organs and tissues of polecats (Mustela putoris L.) from the Netherlands. Environ. Toxicol. Chem. 13: 129-142

[22] Bosveld, A. T. C., Gradener, J., Murk, A. J., Brouwer, A., van Kampen, M., Evers, E. H. G., Van den Berg, M. (1995): Effects of PCDDs, PCDFs and PCBs in common tern (Sterna hirundo) breeding in estuarine and coastal colonies in the Netherlands and Belgium. Environ. Toxicol. Chem. 14 (1): 99-115

[23] Jones, P. D., Giesy, J. F., Newsted, J. L., Verbrugge, D. A., Beaver, D. L., Ankley, G. T., Tillitt, D. E., Lodge, K. B., Niemi, G. J. (1993): 2,3,7,8-Tetrachlorodibenzo-p-dioxin equivalents in tissues of birds at Green Bay, Wisconsin, USA. Arch. Environ. Contam. Toxicol. 24: 345-354

[24] Yamashita, N., Tanabe, S., Ludwig, J. P., Kurita, H., Ludwig, M. E., Tatsukawa, R. (1993): Embryonic abnormalities and organochlorine contamination in double-crested cormorants (Phalacrocorax auritus) and Caspian terns (Hydroprognec caspia) from the upper Great Lakes in 1988. Environ. Pollut. 79: 163-173

[25] Daelemans, F. F., Mehlum, F., Lydersen, C., Schepens, P. J. C. (1993): Mono-ortho and non-ortho substituted PCBs in arctic ringed seal (Phoca hispida) from the Svalbard area: analysis and determination of their toxic threat. Chemosphere 27 (1-3): 429-437 